\title{
Hamilton Depression Rating Scale-24 Item Clinical Classification
}

National Cancer Institute

\section{Source}

National Cancer Institute. Hamilton Depression Rating Scale-24 Item Clinical

Classification. NCI Thesaurus. Code C130307.

A standardized 24-item rating scale for the assessment of symptoms in patients diagnosed with depression. The original 17-item Hamilton Depression Scale, developed by Max Hamilton at the University of Leeds in 1960, was later modified to include 24 variables. 